\title{
MYTHS \& BELIEF IN SRI LANKAN SOCIETY \& THEIR EFFECTS ON WOMEN
}

\author{
Nadeeja Abeyasekera $^{1 *}$ and Chanaka De Silva ${ }^{2 * *}$ \\ ${ }^{1,2}$ Sri Lanka Foundation Institute
}

\begin{abstract}
Beliefs are born within the people of a community, society or a country. Beliefs can be both, true or false. People cling on to beliefs as they want to make themselves happy and satisfied. In The case of Sri Lanka, beliefs are tied to specific religions -Buddhism and Hinduism. Myths on the other had come down generations and tend to be tied to historical incidents. Different types of beliefs are harbored within individuals, from different areas within the same country. They are passed down generations and change from area and community.

Migration for commerce and improved opportunities means more people populate the Western province now than before. In typical patriarchal societies that are usually found in most Asian countries some traditional practices are based on beliefs and myths, and are both harmful and degrading towards women.

How does age-old thinking affect the women of today? The paper looks into common beliefs, myths and traditional practices of Sri Lanka and how they affect the progress of girls into womanhood. The study links beliefs, myths and traditional practices to the lives of women from both rural and urban settings, to understand how they shape the image of a 'woman' in Sri Lankan society.
\end{abstract}

Keywords: Myths, Beliefs, Traditional Practices, Women, Asian Cultures, Sri Lanka

\section{INTRODUCTION}

Woven on the loom of traditional and historical experiences is a complex fabric of conventions, beliefs, values, attitudes and prejudices that wind through levels of Sri Lankan society.

Women brought up in traditional or orthodox family milieus, especially middle-class believe that such sentiments are natural phenomena and are unable to see them as attributes of their social-economic background. Many women have defined their lower status as their destiny, because it is inscribed in their religious beliefs. HemaGoonatilake explains this as a struggle against accepted customs, values, attitudes and prejudices arising from various historical experiences. Women are taught to accept certain institutions as 'natural' while the man-made codes of behavior provide the seeming rational (Goonatilake, 1976).

Despite recent achievement of been recognized as a Middle- income country progressive social and political development in Sri Lanka over the couple of years, Sri Lankan women continue to occupy a subordinate status. Entering public and private sector one might think that women share equal opportunities and wages as there are so many working in banks, hospital, schools and government institution. Many misinterpret this as an indicator of the status of women in Sri Lanka and argue that women are indeed better off compared with to women of other South Asian countries. However the hidden reality is that on the whole women hold minor positions with low status and pay in the workforce (S Jayaweera, 2007). Instead they are often subject to many discriminatory processes and forces in the work milieu, such as

Corresponding Email: *nadee-abeyasekera@yahoo.com, **chanakyadesilva@ gmail.com 
sexual harassment and glass ceiling ((Hewamanne, 2008)(Jayathilaka, 2006). Many adverse structures and forces such as patriarchal social structures, women's role in the family, traditional values, rituals and myths, the division of labour and unequal pay and women's lack of participation in politics contribute to the continuing subordination of the Sri Lankan women(Herath, 2015). In patriarchal settings most important family decisions are made by males.

Wives seldom enjoy decision making power. After marriage almost all of them are taken to the bridegroom's house which may be the house of the father and mother -in law. One such practice of patriarchal practice that disadvantages women economically is the distribution of the family estate. Since the era of kings, estates have been inherited along the patriarchal kinship line. Daughters receive a dowry while sons enjoy the family estate, although the Kandyan Law clearly accepts women's property law(Ponnambalam, 1982). The Hindu Dowry system has taken a firm place in Sri Lankan society. Dowry where the property given by the bride's parents to the groom becomes the groom's property. However the Sinhalese system of the 'Dayade' is falling back. A system where the property of the remains in her ownership. Even among the Muslims there is a Dowry system preferred over the 'Islamic Bride Price' where the groom has to pay the bride.

In this context a window too is expected to be very meek and mild, calmly bearing her worries and agonies. As in the case of many war windows of the North,in most women-headed household are unemployed even though they are compelled to head families.

The reality the traditional beliefs, attitudes, social practices have kept women in subordinate roles in society is explored in the following sections.

\section{Myths \& Beliefs and Attitudes}

Major impediments to women's progress in life are the paradigms endangered by myths, blind beliefs and patriarchal concepts that hinder their independence and dignity. Many examples could be quoted in folklore in this regard: 'Women are born with weak intelligence', 'the brain power of a woman is spoon's length long', 'Women are the weaker sex' and 'Women are ever changing and therefore not trust
worthy'(Herath, 2015). The present understand of the present Sri Lankan is that these fallacies and negative ideas about women are found in the villages but this is not the case.

According to Obeyesekera(1984), Sinhala children are socialized into practices of shame-fear (lajjabaya) to be ashamed to subvert norms of sexual modesty and proper behavior and to fear the social ridicule that result from such subversion from a young age. Notions of superior morals and undisturbed traditions that village women are naive, innocent (sexually ignorant), timid are unadulterated bearers of Sinhala Buddhist Culture. Men too desired 'pure' women who as supposedly ideal women were ignorant of all things sexual.

There are beliefs related to most of the events of a person's life in Sri Lanka. As people living in different areas have practices that vary, and it can be seen in the rituals for the same event. A common example for this can be seen in the rituals done in child birth. People in Kandy make it a habit to take the newborn child especially if it's a boy to the Temple of Tooth and make an offering in the name of the child. People in some areas in the North-Western province have a habit called 'pinidiyapanam wen kireema'. To a vessel containing coconut oil is added saffron and sandal wood. It is taken to a devale with the newborn child and an offering is done for the child by the adura in the devale.

Even today the birth of a girl is not celebrated in the same way as that of a boy, although this attitude is changing in the urban setting. While the dowry system may be influencing this attitude many still believe that a girl is born as a result of a sin committed in the past births. Therefore the common belief is that one must cultivate more merits during this life to earn the reward of rebirth as a male in the next.

In providing education and developmental skills, the tendency is to bestow these in the male children of the family as they would most probably be providing aging parents with the necessary economic support. A woman may be consoled by having a daughter as an assurance of being cared during their old age. During the course of their upbringing, rural girls are often denied opportunities to make decisions about their 
life. Such a child born equal but raised in a confined environment, may be considered simple and 'backward', not because she is retarded, or physically deformed or psychologically weak but because she has never been given the chance to develop her abilities. A girl brought up in a family holding traditional values will be taught to be polite, innocent, bashful and feminine(Jayawardena, 1994).

\section{Beliefs \& Myths in Legends}

Women's subordinate roles in society is repeated several times over in the annals of history and she is portrayed as one who is incapable of making decisions affecting her life. The use of 'horoscopes' to make predictions of a woman's destiny is highlighted in one of the earliest legends of Lanka. The legend of Prince Vijaya and Kuweni gives evidence to the prevalence of beliefs from ancient times. According to the MahawansaKuweni's horoscope had said that she would one day marry a foreigner. It is said that Kuweni had three breasts and the horoscope had also said that when she meets her destined mate the abnormality will disappear. Kuweni believed this.And when Kuweni met Prince Vijaya, the prediction came true. The Mahawansa says that Kuweni, without first going to see Prince Vijaya and his crew in her true appearance, had disguised herself into that of a bitch of five colours and went towards them. Keeping with the prediction she married and had two children by Prince Vijaya. But Prince Vijaya was not faithful to her, and their marriage failed due to the lack of trust.

Including these folktales in social studies texts for school children and repeated reference to Kuweni (considered a woman of different race than King Vijaya) influence the thinking of both boys and girls. These myths and beliefs may well be leading to the idea that men are privileged while women are subjugated to serve.

Another legend that is historically linked to Sri Lanka and mentioned atleast in fifty places across the country is the legend of Ravana, King of Lanka. Ravanais the primary antagonist in the Hindu epic, the Ramayana. He is depicted as a Rakshasa(demon). In the Ramayana, Ravana kidnaps Rama's wife Sita to exact vengeance on Rama and his brother Lakshmana for having cut off the nose of his sister Shurpanakha.
Although modern times are changing reference to many such legends, myths and beliefs at religious and cultural locations, through illustrations, songs and literature we bring about a culture that promotes unequal power and lack of understanding of the women's position in society.

\section{Beliefs \& Traditional Practices}

When a girl reaches puberty, according to Sinhalese and Tamil traditions there in a common belief that she should not be seen by male until a purification ceremony is performed at an auspicious time matching her horoscope to bring her out of the room she has been isolated. Rituals involve breaking of a coconut, dressing the girl in white cloth for purity and getting a woman of a lower caste (the 'dhobi' or laundry woman) to bath the girl are considered important for the occasion. The occasion is celebrated after two weeks of her first menstruation and 'bathing ceremony' and many presents mainly gold jewelries and nice clothes are gifted at a function where men folk also attend. While predictions given by the Gurunnanse(respected teacher) based on the horoscope reading is expected to guide the girl's life through womanhood the party itself advertises the availability of a girl who is ready to get married.

Menstruation is considered impure (killi) and girls and women are isolated during religious performances in Kovil and Devale. These beliefs have been an influence on Buddhist ceremonies as well which is one of the reason men are given precedence over women to perform religious rights during all night pirith chanting, bana(reciting of damma) and dana (offering of meals to Buddhist monks). Generally the pollution (killi) caused by death lasts three months, by child birth one month, by a maid attaining age fourteen days and by monthly turn of women till she bathes.

People who believe in materialistic sciences may show uncertainties about the beliefs. But still almost everyone engages in auspicious activities in functions like the inauguration of building a house. People believe that there are bahirawas(deity) living in the ground and that by building a house in a place, they are capturing their habitats. As an excuse and an offering is common practice to hold a bahirawapooja, before building a house. It relieves the minds of the 
doers, that no one is angry over the building of the house in that place. The story about the building of Ruwanweliseya(Buddhist Chaitya in Anuradhapura) in a place where a 'ruk devathawa' (a goddess living in a tree) resided and naming the stupa following her name is a famous example for offerings done before building on a land.

The case of Sriyani of IhalaMadurangala, Badureliya illustrates the importance attributed to such traditions:

Sriyani Padmini (42) of Palindanuwara is a woman of a woman-headed household and member of a lowincome family. She was fortunate that a few philanthropists combined to support her in putting up new house in order to provide security for the aged mother and two adolescent children. Before work could commence on construction the woman spend part of the money give for the house to conduct the traditional bahirawapoojain the presence of the village people. 'Partly this is considered a norm in the area' commented Wanigatunga, a civil society leader 'and to a great extent their ignorance and fear of the unknown in villagers. What you don't see you believe!'

Beliefs can be true or false. People cling on to beliefs as they want to make themselves happy and satisfied. Another example of people's attempt in safeguarding things they value highly is the traditions followed when a new vehicle is bought.People in Sri Lanka commonly belief that 'aswaha,katawaha' (evil eye, evil words) can be warded off by tying chilies and limes strung with a piece of wire on the front buffer of the vehicle. They also go to the Kataragamadevale and tie a pandura (coin) to obtain protection. However everybody understand that neither the vehicle nor the passengers are actually safer because of this yet the practice continues.

NishaniJayampathy (28) is an educated youth residing in urban Piliyandala, a Business Executive in a leading corporate. His comment on this ritual explains how people in urban settings feel about performing rituals.

'When I bought my first car a Nissan March I was so proud of my achievement even though it was purchased with the help of a small loan from my office. My parents insisted on me taking it to the devale and tying a padura(offering) and performing a pooja for blessing on the new possession. I did all these and never had any issues regarding my car.'

We could assume that motivated by ritualistic actions people are more careful of the usage of material things they value and hence look after what has received with blessing for protection with meticulous care.

\section{Healing Rituals \& Traditional Practices}

There is a strong belief among ritual dance performers that there is a massive transformation in them both mentally and physically, a kind of a trance when they wear a ritual mask and dance, to the tune of the drums.Both, the patient afflicted by the evil spirits and the Kattadiya are also under a trance in the height of the ritual performances. The blasting sounds of drums, the burning of incense and of numerous verses create a bizarre atmosphere suitable for the ritual. It is a common experience of those who have watched the Gam Madu ritual performed annually in many parts in Sri Lanka that even onlookers could be seen in ecstasies.

Even today Sri Lankans accept, both the native system of treatment and healing rituals as effective ways of curing ailments. Mostly in the rural sector Thovil the healing rituals are practiced.It is evident that mask carving and mask dancing coexisted with exorcism and Ayurveda since very ancient times.

During the elaborate procedure numerous verses are recited and the silence of the whole area from evening to dusk is disturbed by the deafening sound emanating from the beating of drums. Kolam dance performance is comprised of numerous episodes and diverse characters perform their roles representing the traditional rural setting of Sri Lanka in addition to their sufferings under the colonial administration.Members of the traditional hierarchy of Sri Lankan royalty and all categories of servants appear on the stage where the Kolam dance is performed. Before the arrival of the King and Queen the Headman, the Chief of the district, the Mudali, Arachchi, theKing's Guard and the soldiers make suitable arrangements on the stage for the arrival of the royalty.

There is a popular myth related to the origin of Kolam dance. The consort of the imaginary King 
MahaSammatha had been affected by pregnancy craving to see a mask dance but in that era nobody in his kingdom had seen or heard anything of mask dances. Day after day the condition of the Queen became worse. Realizing the plight of the Queen, God Sakra requested God Visvakarma who was considered as the divinity of arts and crafts to invent masks and the lyrics for the mask dance to satisfy the desire of Queen Mahasammatha.

The following morning masks and lyrics for Kolam dance form were found in the royal garden. King Mahasammatha ordered his kingsmen to study the lyrics and perform the Kolam dance. Queen Mahasammatha was happy and satisfied after watching the Kolam dance and her pregnancy cravings disappeared. In Sri Lanka wherever Kolam dances are performed this mythical origin has been highlighted by the arrival of the pregnant Queen towards the stage. All verses used in the Kolam Dance form are full of sarcasm and punning on words by the characters and the masks worn by them are rich enough to make the audience hilarious throughout the performance.

AlthoughKolom dances and masks worn during ceremonies add to the rich cultural heritage of Sri Lanka,as with legends and common beliefs is contributing to the prevailing social norms and attitudes that negatively portray women in society. While exorcisms and a limited number of supernatural powers are granted on women, in general it is the men (kattadiyas) who perform rituals and Kolam dances, and this has been the tradition right throughout. Two examples drawn from the scripts of Kolam dances are given below to illustrate the portrayal of women:

Gama Kathawa (village story): A pregnant woman narrates how she became pregnant in one of the episodes of Kolam dance full of humour. In this episode, the village headman abusing his powers made amorous advances towards a married woman known as Ethna Hami. There were two foolish brothers in the village and the elder brother got married to EthnaHamy. In order to get rid of her husband the village headman said that the King had ordered to send the two brothers every night to look after some far away fields.
One day when they were guarding the fields these two foolish brothers mistook moonlight as sunlight and came home thinking it was morning. EthnaHamy did not open the door at once but first covered her lover the Village Headman with a cloth. Next she covered herself with the cloth to cover up her identity. She pretended to be mad and an exorcist who happened to be a friend of the Village Headman appeared to drive away the evil spirits. During the ritual the Village Headman appeared disguised as a demon and frightened the two brothers who ran away from the scene. Later EthnaHamy and the village headman started dancing together.

The story behind a second Kolam dance is given below.

In BadadaruKolama(Pregnant woman's story) a pregnant woman appears on the stage crying and complaining of pregnancy pains. Kariyakaravana (narrator) asked her to stop her crying. She responded saying that all men in the audience were responsible for her condition. They promised to give her clothes and jewelry wishing to marry her but they never kept to their promises. KariyakarawanaRala (narrator) admitted that she had been cheated by the men and her suffering was also due to their misbehavior.Arrangements were made to get down a midwife who helped her to give birth to a child. She appeared once again on stage this time with the new born baby in hand.

As Hewamanne(2008) explains the beliefs among garment factory girls in the FTZ rural Sri Lankan women desired marriage and sincerely believed that their relationships with their boyfriends (soldiers) would end up in marriage. Although they firmly held that their boyfriends were not bad men, workers knew these relationships could result in misery and even tragedy. Given the dominant culture expectations of staying a virgin until marriage and the taboo on premarital sex, women frequently talked about men having sex with women and then abandoning them as a crime (aparadayak). Ironically the same word is used for the actions of a man in the case of rape, murder or any crime.Leaving the victim to battle with the trauma of the violence meted and the stigma that follows survivors of rape. 
The Temple of the Tooth in Kandy is well known for the religious and cultural value that has stood for time immoral since when the place was erected to host the 'tooth' of the Buddha. The annual Perahara during August marks and important cultural event for Sri Lankans and tourists alike. The final of the Kandy EsalaPerahera is marked by the Walli Yak Mangalya at the Maha Vishnu Devale, which is performed for seven consecutive days. At the end the performance GaraYaka appears at the Maha Vishnu Devale where he has been called by the performing dancers and seeks a prey to depart in peace.During this period of seven days, those villagers who know the existence of the ritual come to offer vows and also make vows. These vows are tied on the 'tail' of the Yakdessa's headgear and not at the devaleproper. Those who come, redeem the vows they have made the previous year which have been successfully granted, and go back satisfied.

It is no secret that young women are brought by their mothers to tie vows in search of their future husbands, and in numerous instances these have come true. Again and again traditional practices are making women in our society take on subordinate roles and enter into marriages which seems to be set on god's favour, dowry ordue to the girl's beauty and acquired feminine qualitiesthat was described earlier.

Three sources of superhuman influence from which the Sinhalese pleasantry expects good or ill are (1) the spirits of disease and poverty (2) tutelary spirits of various grade and (3) planetary spirits. According to Arthur Pererathere are several important spirits of disease such as MahasonaYaka, RikiYaka, Kalu Kumara Yaka and SanniYakka. Mahasona inflicts disease like Cholera and Dysentery and presides over graveyards and where three roads meet.

According to folklore in ancient times two giants Jayasena and Gotimbhara met in single combat and the later knocked off the head of Jayasena, The God Senasura tore off the head of a bear and placed it on Jayasena's body who rose up alive as the demon Mahasona.(Perera, 1917). The study of traditional practices and beliefs in the rural villages in Kalutara district showed that people are reliant on favour from these spirits to solve day to day problems such as sickness, delayed marriage of girls, blocks in the progress of attainments in education, social status and business. The Kattadiyas who perform these ritualsseems to be exploiting their fears and taking advantage of their despaired situation to earn money. As one leader in of a civil society group in Palindanuwara, Kaluthatra, Wanigatunga said "people's beliefs and traditional practices is one of the contributors to their perpetuation of poverty".

The book on Sinhalese Folklore. Arthur Perera(1917) illustrates the character and capabilities of the four sprits in this manner:

KaluKumaraya is a young devil of dark complexion who is seen embracing a young woman; he delays conception, child births and causes puerperal madness. There was once a Buddhist monk who was Arhathwith super natural power of going through the air. In one of his aerial travels he saw a beautiful princess, fallingin love with her lost at once his super powers dropped down dead and became the demon KaluKumaraya.

RiriYakaa monkey faced demon that carries a cock in one hand, and a club in the other with a corpse in his mouth is present at every death bed and haunts fieldscauses fever, flux of blood and loss of appetite and has a crown of fire on his head.

SanniYaka has cobras twisting around his bodies with a pot of fire near him, holds a rosary in his hand and holds a trinity with OddiYaka and HuniyamYaka. He was a son of a queen put to death by her husband who suspected she was unfaithful to his bed. As the queen who was pregnant was being executed she said, that if the charge was false the child in her womb will become a demon and will destroy the King and his city. Her corpse gave birth to SanniYaka who inflicted mortal disease on his father and depopulated the country.

When any of these devils have inflicted a human the prescribed form of exorcism is a devil dance. The ceremony consists of a series of brisk dances by the exorcist and his men, in the presence of the patient to the accompaniment of chants (kavi) giving the life history of the devil with a twirl of blazing torches. This lasts from evening till dawn till the exorcist lie on his back and calls on the devil to cure the patient (yadinna), incantations follow (mantra) and the sacrifices follow. For RiriYaka a cock which has been placed under the altar or tied to the foot of the patient 
is killed and thrown into the jungle. For KaluYaka an earthen pot which has been placed on the altar is broken, for SanniYaka the offerings are conveyed in a large bag and thrown to a stream or river, for MahaSona the exorcist feigns death to deceive the devil and is carried with mock lamentations to a burial ground.

Kattadiya is believed to be more than just a witchdoctor, s/he is an exorcist between the worlds of human and devils and to some the answers to every problem. While all the devil dances, rituals and ceremonies make Sri Lanka a rich and interesting culture-hub, these charlatans do nothing but exploit the ignorance and fears of hapless people who don't know any better. Various intricatethovil ceremonies are costly business and the Kattadiyas are enjoying a flouring ventures while steadily draining their clinets money. Both in rural and urban setting people's beliefs in the supernatural are in many cases been the barriers to realistic problem solving and progress in life.

Of the four spirit mentioned the Kalu Kumara is seen mostly affecting virgins. According to folklore a young girl should not walk at dusk or fry any sweetmeats also at this time less the devil possess you. Many are the stories coming from rural villages where young girls who have supernatural bindings with this dark demon and the mothers take them to the devaleKupuralato get rid of the possession by spirit and to be free of its malicious grasp of the young girl. The belief in this lesser God is highly detrimental to girls who have come-of -age, as it prevents them from leading normal lives, socializing with people and restrains the development into a confident woman. As the parents especially mothers become over protective, girls who have been told that they have been possessed by the KaluKumarayaeventually do develop a certain repulsiveness towards males and as a result of the narrow-thinking do not mature sexually. It is no wonder that women possessed by the KaluKumaraya (Dark prince) is said to kick their husbands off their bed and suffer from problems in conception. It is a clear case in which not only do the beliefs affect the girl concerned but also others who partner her in life making it impossible for normal family life.
One case of a woman in Bulathsinhala, Kalutara is woman who now operates as a spiritual doctor herself. She came under influence of the KaluKumaraya at the age of 15 years. TanujaPadmini (35) said:

Her mother took her toseveral places to do a gurukama,but they failed. It was an Adurek (witch doctor) in Ratnapura who was able to cure her from being 'possesses', delirious and acting crazy. Prior to this she was awarded at the mental hospital in Angoda for treatment. People who get treatment at the Mental hospital are considered crazy and sometimes even cornered in society because of the fear in others that they too may become crazy and lose control.

Her beliefs and experiences later led her to been an agent dealing with spiritual and supernatural powers to bring healing in patients, making wows, and keeping wows (a Pooja when something you ask for is given), breaking of bandana(bindings), dehikapanawa (cutting of lime to remove spells). In her aid is a 'istadevatha' a minor deity, who's often a close relative believed to be protecting help Tanuja in seeing into what has taken place and making predictions into the future ('penakiyanawa').Something similar to crystal gazing is attempted by means of a betel leaf smeared with a magical oil; a female deity (Anjanan Devi) appears on the leaf and reveals what the gazer seeks.

For Tanuja the talent she has inherited does not give her much gain economically because she has decide to use her gift to heal people who like her were possessed by demons or came under a spell done my enemies. However visiting her home nested in a rubber estate, revealed that she now received respect from the villages. This further strengthens the belief of the village people in myths and traditions and that these are closely interwoven into the fabric of their lives, challenges and daily routines.

Tanuja had erected small pillar boxes for three minor gods and had one main devale built in the garden to host the five main Gods. Inside each of these places were small statues or framed pictures depicting Gods and in front of these oil lamps were lit in their honour. She meticulously sweeps and cleans the area and on the day of our visit had the applied a mixture 
of cow-dung and clay to purify the premises. Although the mixture smells of a few days when dried it is supposed to be having antibacterial function and serves well in areas that are frequented by many people.

Tutelary deities are of three of grades according Arthur they are (1) Gods (2) Godlings and (3) Devine Mothers. The Gods are MahaDeviyo, NathaDeviyo, KataragamaDeviyo, SamanDeviyo and Goddess Pattini.

MahaDeviyo is identified with Vishnu, andis the guardian deity of the island, and is acandidate for the Buddahood ; a miniatureweapon in gold or silver is placed at hisshrine as a votive offering.

NathaDeviyo is the future Maitri Buddhaand is now biding his time in the Tusitaheaven;Kandyan sovereigns at their coronation girt their swords and adopted theirkingly title before his shrine.

SamanDeviyo is the deified half-brotherof Rama, who conquered Ceylon in prehistoric times, and is the guardian spirit ofAdam's Peak; pilgrims while climbing thesacred hill to worship Buddha's footprint, call on him to aid their ascent. A miniatureelephant in gold or silver is the usual votiveoffering to him.

KateragamaDeviyois the most popular of the gods; a prehistoric deity, to whom aminiature peacock in gold or silver is thecustomary votive offering. He is said to bethe six faced and twelve handed god Kandaswamy who on his homeward return toKailasa after defeating the Asuras halted atKataragama in South Ceylon; here he met his consort ValliAmmawhom he wooed inthe guise of a merchant; when his advanceswere scornfully rejected, his brother assuming the body of an elephantappeared on the scene and the terrifiedmaiden rushed into her suitor's arms forsafety; the god then revealed himself and shebecame his bride. The god Ayiyanar invoked in the forests of Ceylon is said to be hishalf-brother.

Pattini is the goddess of chastity. The three eyed Pandi Raja of Madura had subjugated the god and was getting them to dig a pond near hisroyal city when, at Sakraya's request,Pattini who resided in AvaragiriParvatabecame conceived in a mango fruit. Afterit was severed from the tree by an arrow
ofSakraya, it remain suspended in the airand on Pandi Raja looking up to observethe wonder, a drop of juice fell on the thirdeye in the middle of his forehead by whichhe lost his power and the gods were liberated.Pattini was found inside the mango as aninfant of exquisite beauty sucking her thumb when she grew up she performedwonders and ultimately disappeared within a Kohomba tree (Margosa). An armlet or aminiature mango fruit in gold or silver isplaced at her devala as a votive offering.

These deities are usuallyworshipped in separate devalawhich are in charge of Kapurala. Since ancient times devales have been inside temples due to the direct influence of Hinduism in Buddhism and the intermingling of beliefs in these two major religions. Occasionally they are found in homes and places specially setup to do witch craft such as Tanuja's place.

Off these Gods women and girls specially seek favours from Goddess Pathini to become as beautiful and fair in complexion, to find suitable marriage partners and to have children. Another Goddess found more commonly in Hindu temples but also in Buddhist temples is Goddess Kali. She is a frightful blue skinned female deity holding weapons and corpses in multiple hands. The Goddess is used to seek revenge and engage in battle.

One woman spoken to in a village in Kalutara recalled an experience of abuse during her childhood. She said:

When I was eleven years old, a complete stranger came up behind me and put one hand down my shirt and the other between my legs. He made a sort of chirping noise, a "come on" sound like you'd make to a sluggish animal. This being prior to my current nonviolent phase, I turned around and punched him in the face.

I imagine that every girl who experiences molestation or rape must have a voice (internal or external) that chirps up and says "that wasn't really rape" or "it wasn't rape enough" or it wasn't "forcible" or "it was just teasing".People even deny it could never have happened only a crazy child would lash out when she is teased - but for me it felt good to have my defense. It's hard enough to call it rape in the privacy of one's own head and heart. It is hard to face oneself in the 
aftermath, much less one's attacker and detractors. Do you tell your mother? Does your faith fail you or help you forward?

I see strong-looking divine ladies that are role models to our broken selves. When we feel like a helpless child we must become the fierce mother. Kali, bristling with weapons and dripping with blood, looks like something I need to conjure in myself: a spiritual warrior to defend me from further harm.

Eve-teasing and sexual harassment is not uncommon in the country. The culture and traditional practices does nothing in support of giving a positive image of a woman. Mother in families who have adolescent sons also do nothing to groom her sons to respect and understand females but continue to spoil them because of Patriarchy the 'boy' child is always favoured.

Kem methods, are another belief used in healing diseases in humans, animals and to protect the harvest. This is described as a non- logical practice, in which the reason why and how the results are obtained cannot be sensibly explained. However kem methods are commonly used even nowadays and results are gained if done correctly.

Beliefs which bring misfortunes belong to the black magic type are called gurukam. Diva ugurubandeema(sore throat) is an example for this black magic where the voice and the talent of speaking is cut off by a kattandiya. It is said that singers and talented speakers requested the kattandiya not to do diva ugurubandeema for them, before participating in an event, in the past. Also a person doing washi gurukam can make a person become very sick suddenly, or make a woman fall amorously for a particular man. These spells when noticed must be terminated through the consultation of a witchdoctor.

Wisabandeema(blocking the poison) is another belief, which is done by a village vedamahattaya (Ayurveda doctor). When a person has been stung by a snake, and taken to a vedamahattaya in a different village, the vedamahattaya of the patient's village considers it a disgrace to him, and does wisabandeema, which make medications ineffective for the patient. Since this is a known fact, the patient is advised to see the village wedamahattaya, by the consulted non-native wedamahattaya.Kali meniyo is considered a spirit which helps in punishing an enemy.

The third supernatural power that all Sinhalese believe in is the effects of the planetary forces. According to Arthur Perera (1917) Planetary spirits influence the life of a person according to their position in the heavensat the time of his birth. This could be found out by keeping a small amount folded on a beetle leaf and the Gurunnanse (Astrologer) will read the birth chart/ horoscope to foretell the future. Sri Lankan go to extremes in using this as a tactic to plan their lives like finding educations avenues to pursue, suitable marriage partners and ways and means of warding off mal-effects coming from various planets. This is usually done by doing bodhipoojas,baliya and wearing a ring with a matching stone to counteract planetary forces.

The planetary forces are recognized as:

- Sun (Ira) rides on a horse entwined with cotton leaves (Imbul) with an emblem of good luck (Sirivasa) in hand and propitiated by the Santi MangalaBaliya; sacred to him is the ruby (Manikya).

- Mercury (Budahu) rides on an ox with a chank in hand, entwined with Margosa leaves (Kohomba) and propitiated by the SarvaRupaBaliya; the emerald (Nila) is sacred to this planet.

- Mars (Angaharuva) rides on a peacock with an elephant goad (Unlmsa) in hand, entwined with gamboge leaves (Jcolon) and propitiated by the Kali MurtaBaliya; the coral (Pravala) is sacred to this planet.

- $R a h u$ rides on an ass with a fish in hand entwined with screw pine leaves (Vetakeyiya) and is propitiated by the AsuraGiriBaliya; the Zircon (Zomada) is sacred to Rahu.

- Kehetu rides on a swan with a rosary in hand, entwined with plantain leaves (Hemi) and is propitiated by the Krishna RakshaBaliya; the Chrysoberyl (Vaidurya) is sacred to Kehetu. 
- Saturn (Senasur.) rides on a crow ; with a fan in hand entwined with banyan leaves (Nuga) and is propitiated by the DasaKrodhaBaliya ; the Sapphire (Indranila) is sacred to this planet.

- Venus (Sikura) rides on a buffalo with a whisk (chamara) in hand, entwined with Karanda leaves (galidupaarborea) and is propitiated by the GiriMangalaBaliya; the Diamond (Vajra) is sacred to this planet.

- Jupiter (Brahaspati) rides on a lion with a pot of flowers in hand, entwined with $B o$ leaves and is propitiated by the AbhayaKalyanaBaliya; the Topaz (Pusparaga) is sacred to Jupiter.

- The moon (Chandra) rides on an elephant with a ribbon in hand entwined with Woodapple leaves (dimbhul) and propitiated by the Soma MangalaBaliya; pearls (Mittu) are sacred to the moon.

Horoscopes are consulted for the birth, attending-ofage, and marriage, and during bad spells of life by a woman. Those Astrologers look at a horoscope of a woman differently from a man, of a girl child differently from a boy child because traditions and culture define them in gendered roles. These interpretations of future happening can work well or adversely for a woman. Being a strong believer of this supernatural power can make a woman already who's subordinated in her role in home and office space feel helpless - which when the horoscope reader suggests seem witchcraft could salvage the situation.

Some ceremonies cost huge amounts of money. Alsomantras place on rings made with matching stones to counteract ill forces or mantras, placed inside of small metal talismans known as Suraalthough expected to lessen problems, add to the cost affairs. A woman who is waiting to get married may use most of her saving to employ tactics to find a suitable partner, a mother will spend more money on bali than on extra classes in supporting her children's education and an average family may spend nearly as much on consulting medical doctors as with the witch doctor in order to help someone with sicknesses.
Whether in the city, suburban or rural setting this pattern has not lessened in spite of great strides in technology and development.

Beliefs and traditional practices stand strong today as it was in the period of Arthur Perera's book on Folklore of Sinhalese (1917)

\section{CONCLUSION}

Beliefs are very important for the good maintenance of society, as they bring about a rich culture and a strong bond among people. On the other hand myths, beliefs and traditional practices in our country that is interwoven with patriarchal structures andthe historical experiences are observed to bedetrimental to women. Several examples of mythical stories and traditional practices explained such as kolam, bali, thovil and Shanthi karma, are portraying women in a negative light. At a time when many civil society groups and a number of noteworthy personsare attempting to share the rights and privileges equally with women, it seems age old beliefs, myths, and traditional practices are gravitating these efforts from reaching the desired goal posts.

The fact that these traditions are strongly believed by people from different levels of society and that both men and women areequally in favour of beliefs in the supernatural powers than on reality means breaking away from these milieu is a challenge ahead of us.The danger in seeking solutions using various forms of exorcism and witch crafty is that victimized women (and men) are likely to believe their fate was decided by these the gods and planetary conjunctions.

There is source of inspiration in the message given byLigiaBolvar (1998) “The dignity of the individual is immutable; it is the same all times and in all places, and its essence transcends cultural particularities" as we attempt to give women their due place in Sri Lankan society.

\section{REFERENCES}

Bolvar, L., 1998. The Fundanemtalism of Dignity. Stockholm, The Ministry of Foreign Affairs of Sweden.

Goonatilake, H., 1976. Social and Political Participation: Tradition, prejudice, myth, reality. Economic Review, 2(6), pp. 16-17. 
Herath, H. .. M. A., 2015. Place of Women in Sri Lankan Society: Measures for their Empowerment for Development and Good Governance. VJM, Vol.01(1) 01-14(1), p. 1.

Hewamanne, S., 2008. Stitching Identies in a Free Trade Zone: Gender and politics in Lanka. Philadelphia, University of Pennsylvania Press.

Jayathilaka, A. W. \&. W., 2006. Beyond the Glass Ceiling and Brick Walls Gender at the Workplace, Colombo: ILO.

Jayawardena, K., 1994. Religous and Cultureral Identity and Construction of Sinhala Buddhist Womanhood. Nevidini, 1(1), pp. 111-139.
Obeyasekera, G., 1984. The Cult of the Goddess Pattini. 1 ed. Chicago: University of Chicargo Press.

Perera, A., 1917. Sinhalese Folklore Notes - Ceylon. Kandy: s.n.

Ponnambalam, S., 1982. Laws and Marriage RElationship in SRi Lanka. Colombo: Stanford Lake Publication.

S Jayaweera, H. W. L. W. \&. K. M. V., 2007. Gender Dimensions of Decelopment Goals in Sri Lanka, Colombo: CENWOR. 